\title{
Linfoma angioinmunoblástico de células T
}

\author{
Angioimmunoblastic T cell lymphoma
}

\section{Sr. Director:}

Recientemente Pereira C y Tavares N han publicado en su revista un caso muy interesante titulado "Linfoma angioinmunoblástico de células T" en un varón de 93 años. Nos gustaría realizar algunos comentarios al respecto. Este tipo de neoplasia representa 1-2\% de todos los linfomas no-Hodgkin y el $15-20 \%$ de los linfomas de células T periféricas². En el estudio inmunohistoquímico la población linfoide es positiva para CD2, CD3, CD4, CD10, CXCL-13, PD1 y, con frecuencia, para BCL-62 ${ }^{2}$. El linfoma angioimmunoblástico de células $T$ es una enfermedad sistémica que afecta a ganglios linfáticos, bazo y médula ósea ${ }^{3}$ y que con frecuencia se asocia a fenómenos autoinmunes, entre los que se encuentran inmunocomplejos circulantes, aglutininas frías, anemia hemolítica, factor reumatoide y anticuerpos antimúsculo liso². Se estima que la mitad de los pacientes hay hipergammaglobulinemia policlonal.

Se trata de un linfoma muy agresivo, con una mediana de supervivencia en torno a los 3 años. En cuanto al tratamiento, se han ensayado varias modalidades terapéuticas entre las cuales se encuentran los corticoides, los fármacos citotóxicos (vorinostat, romidepsin, panbinostat y belinostat) y los inmunomoduladores (rituximab, lenalidomide) ${ }^{2}$.

\section{Bibliografía}

1. Pereira C, Tavares N. Linfoma angioinmunoblástico de células T. Galicia Clin 2015;76(4):182-183.

2. Massimo F, Rudiger T, Bellei M, Nathwani BN, Luminari S, Ciuffuer B et al. Clinicopathologic characteristics of angioimmunoblastic T-cell lymphoma: Analysis of the International Peripheral T-cell Lymphoma Project. JCO January 10, 2013 vol. 31 no. 2 240-246.

3. Attygalle A, Al-Jehani R, Diss TC, Munson P, Liu H, Du Mq et al. Neoplastic T cells in angioimmunoblastic T-cell lymphoma express CD10. Blood 2002;99:627-633.

\section{Gargantilla $\mathrm{P}^{1,2}$, Martin $\mathrm{BM}^{1}$, Pintor $\mathrm{E}^{2}$}

${ }^{1}$ Servicio de Medicina Interna. Hospital de El Escorial de Madrid ${ }^{2}$ Universidad Europea de Madrid

${ }^{3}$ Servicio de Ginecología y Obstetricia. Hospital Universitario Fundación de Alcorcón

Correspondencia: pgargantilla@yahoo.es

Como citar este artículo: Gargantilla P. Martín BM, Pintor E

Linfoma angioinmunoblástico de células T. Galicia Clin 2016; 77 (3): 149

Recibido: 25/12/15; Aceptado: 26/12/15

\section{Normas de publicación Galicia Clínica}

Galicia Clínica es la revista oficial de la Sociedad Gallega de Medicina Interna (SOGAMI). Se publican 4 números al año, simultáneamente en papel y en www.galiciaclinica. info, incluyéndose en el segundo de ellos las comunicaciones enviadas a la correspondiente Reunión Ordinaria de la SOGAMI.

GALICIA CLÍNICA evaluará para su publicación trabajos médicos relacionados preferentemente con la Medicina Interna y sus subespecialidades, $y / 0$ con problemas médicos prevalentes en la Comunidad Autónoma de Galicia. Se admitirán para evaluación trabajos en castellano, gallego, inglés y portugués.

Para el envio de originales se ha habilitado un formulario en la pagina web wnw.galiciaclinica.info. El sistema confirmará la entrega y permitirá consultar el estado del manuscrito. No se aceptarán originales enviados por otros métodos.

El comité editorial, eventualmente con la ayuda de revisores extemos, evaluará los trabajos enviados decidiendo si procede su publicación, si es necesario realizar correcciones o si se desestima la publicación. Una vez aceptado, se enviarán al autor las pruebas de imprenta para la corrección de posibles erratas.

Los trabajos reunirán los requisitos de uniformidad habituales en revistas biomédicas. Dichos requisitos se pueden consultar en "Uniform Requirements for Manuscripts Submitted to Biomedical Journals: Writing and Editing for Biomedical Publication, Updated April 2010", disponible en http://www.icmje.org. Se recomienda encarecidamente leer en especial la sección "Preparing a Manuscript for Submission to a Biomedical Joumal" (nttp://mww.icmje.org/manuscript_1prepare. $\mathrm{html}$ ) y seguir fielmente sus indicaciones a la hora de redactar el trabajo a enviar.

Se recomienda el empleo de los programas más habituales de edición de texto (Ej)., Word) tanto para el texto como para las tablas.

Dado que la mayoría de las páginas se imprimen en blanco y negro, se aconseja evitar en tablas y figuras en la medida de lo posible el uso de colores o tramas que no tengan el adecuado contraste para su identificación.

Las figuras o imágenes se enviarán en archivo aparte, como archivo de imagen (jpeg o similar) o como PDF con una resolución de 300 ppp. a tamaño de impresión definitivo.

\section{La revista presenta las siguientes secciones:}

\section{Editoriales}

Habitualmente encargados por la dirección de la revista. Su extensión máxima será de 8 páginas de 30 líneas y se admitira una figura 0 una tabla y quince citas bibliográficas.

El número máximo de firmantes será de dos.

Originales

Trabajos de investigación sobre cualquier aspecto médico. La estructura general de los trabajos será la tradicional: Título: en el idioma original y en inglés, Resumen y Abstract en inglés, Palabras clave y Key words (que deben corresponder a los

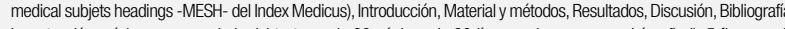
La extensión máxima recomendada del texto es de 20 páginas de 30 lineas, a las que se podrán añadir 5 figuras y 5 tablas, y un máximo de 30 citas bibliográticas.

El número máximo de firmantes será de ocho.

Originales breves

Trabajos de investigación que por sus características no precisan un mayor espacio. Estructura simiar a la de los originales. Su extensión máxima será de 10 páginas de 30 lineas, 3 figuras, 3 tablas y 20 citas bibliográficas.

El número máximo de firmantes será de seis.
Revisiones

Habitualmente encargadas por la dirección de la revista. La extensión máxima recomendada del texto es de 30 páginas de 30 lineas, a las que se podrán añadir 6 figuras y 6 tablas, y un máximo de 50 citas bibliográficas.

El número máximo de firmantes será de tres.

Preguntas clínicas

En esta sección se tratará de responder de forma concreta y sucinta a preguntas clínicas concretas que, bien han motivado una controversia, o cuestionan actitudes arraigadas en la práctica diaria. La extensión máxima será de 6 páginas de 30 lineas, dos figuras y dos tablas y 15 citas bibliográficas.

El número máximo de firmantes será de dos.

Notas clínicas

Descripción de casos clinicos de excepcional interés. Constarán de una breve introducción, caso clinico, y discusión correspondiente. Su extensión máxima será de 6 páginas, 2 figuras y dos tablas y 15 citas bibliográficas.

El número máximo de firmantes será de cuatro.

Cartas al director

Comentarios, opiniones u observaciones sobre los diversos trabajos publicados con anterioridad en la revista. La extensión máxima será de 4 páginas de 30 lineas y se admitirá una figura o una tabla y diez citas bibliográficas.

El número máximo de firmantes será de dos.

Imágenes médicas

Imagenes curiosas, insolitas o demostrativas. Se acompañarán con un texto breve, como máximo 1 página de 30 líneas, en el que se explique el caso clínico, con una breve discusión acerca de la importancia de la imagen.

El número máximo de firmantes será de dos.

Resúmenes de Tesis doctorales

Elaborados por el autor, describirán el trabajo realizado; su extensión máxima será de 2 páginas de 30 líneas. Debe incluirse un apéndice con los datos correspondientes a Universidad, departamento, director de la tesis y fecha de presentación. otros

La dirección de la revista considerará para su publicación cualquier artículo relacionado con la medicina en cualquier aspecto, aunque no se incluya exactamente dentro de los supuestos anteriores. En este caso se recomienda antes de su envio contactar con la direction para acordar las caracteristicas del mismo.

En el caso de que los trabajos enviados incluyan imágenes, figuras, tablas o textos sometidos a copyright, será responsabilidad de los autores la obtención de los permisos necesarios para su publicación.

Todas las opiniones o afirmaciones expresadas en los artículos corresponden a los autores de los mismos. Tanto el comité editorial como la SOGAMI declinan cualquier responsabilidad a este respecto.

Los trabajos publicados serán propiedad de GALCIA CLÍNICA, cediendo los autores todos los derechos a la misma. 